ARTIGO

Recebido em: 20/12/2017

Aceito em: $20 / 06 / 2018$

\title{
Webometria e análise das menções web dos partidos políticos com representação no Senado Federal
}

\section{Webometrics and analysis of web mentions of the political parties with representation in Federal Senate}

\author{
Eduardo SILVEIRA (eduardo.silveira@posgrad.ufsc.br)* \\ Marcio MATIAS (matias97@gmail.com)** \\ * Doutorando em Ciência da Informação pela Universidade Federal de Santa Catarina. \\ ** Professor do Programa de Pós-graduação em Ciência da Informação - PGCIN da Universidade \\ Federal de Santa Catarina.
}

\begin{abstract}
Resumo
Apresenta a aplicação de técnica webométrica nas conexões por menções web dos websites dos partidos políticos com representação no Senado Federal brasileiro. Foram mensurados os indicadores tamanho de website, menções web emitidas e menções web recebidas. Entre os resultados, verificou-se que todos os partidos políticos em estudo possuem conexões na web ou por menções emitidas ou por menções recebidas, sendo o PT o partido que mais menciona os demais partidos em seu website e o PMDB que mais recebe menções. 0 coeficiente de Correlação Linear de Pearson identificou uma classificação forte somente entre a representação dos partidos políticos no Senado e a quantidade de menções recebidas. A análise de conteúdo gerou seis categorias de menções web: Acusação, Votação, Comissão, Eleição, Pessoal e Outros. Conclui-se que as menções web são um registro representativo dos eventos que ocorrem no mundo real dos partidos políticos com representação no Senado Federal brasileiro.

Palavras-chave: Webometria. Menção web. Partidos Políticos.

Abstract

It presents the application of webometric technique in the connections by web mentions of the political parties with representation in the brazilian Federal Senate. It aims to understand how each political party relates to others on the network. We measure the indicators: the size of website, received web mentions and issued web mentions. The results show that all political parties in the study have connections on the web: issued mentions or received mentions; and the PT is the party that most mentions the other parties on its website, and the PMDB is the party that receives more web mentions. The Pearson's Linear Correlation Coefficient pointed a moderate and strong classification between the variables. The content analysis showed that the received web mentions are linked to political issues such, voting, commissions, personal, elections and others. It is concluded that the web mentions are a representative register of the events that occur in the real world of political parties in the Brazilian Federal Senate.
\end{abstract}

Keywords: Webometrics. Web mentions. Political Parties.

\section{INTRODUÇÃO}

A atual conjuntura política no Brasil fez com que milhões de brasileiros expressassem suas opiniões, seja nas ruas ou nas mídias sociais, de norte a sul do país. Nas ruas, indivíduos e grupos contra ou a favor das situações advindas da política nacional promoveram e participaram de manifestações e marchas com gritos de ordem. Nas mídias sociais, que foram amplamente utilizadas para divulgação dos eventos associados ao cenário corrente, ocorreu compartilhamento massivo de notícias, bem como a exteriorização de comentários e de percepções individuais e coletivas.

Muitos dos textos, notícias, áudios e vídeos compartilhados envolveram a utilização de dados incompletos, falsos e/ou fortemente enviesados, e acabaram promovendo a disseminação de informações incorretas no ciberespaço.

Neste contexto, diversos agentes e estruturas políticas brasileiras têm sido bastante questionados pela sociedade e a pesquisa científica pode contribuir para esclarecer a atuação de elementos envolvidos neste ambiente a partir de registros existentes na web. Esta 
informações mais confiáveis na web, dentre eles, os sistemas de recuperação da informação. Estes tratam de:

[...] sistemas de operações interligadas para identificar dentro de um grande conjunto de informações (uma base de dados, por exemplo), aquelas que são de fato úteis, ou seja, que estão de acordo com a demanda expressa pelo usuário (ARAÚJO JÚNIOR, 2007, p. 72).

Um exemplo de dispositivo de busca que recupera diversos tipos de informação provenientes de múltiplas fontes é o Google. Numa busca simples, dependendo do assunto em pesquisa, seja por uma palavra ou expressão, o Google apresenta ao usuário diversos resultados, em geral, pertinentes, publicados em websites, mídias sociais, blogs, dentre outros.

O uso combinado de dispositivos de busca, conhecimentos de estudos métricos da informação em geral e webometria pode fornecer subsídios para uma melhor avaliação de fontes de informação, para a realização de análises mais abrangentes e a compreensão de fenômenos que estão registrados na web, na forma de conexões e menções entre websites.

De acordo com Orduña-Malea e Aguillo (2014) as menções web têm como características a descrição de um termo/palavra na web de forma textual ou hipertextual, sendo elas encontradas em qualquer parte do documento.

Estudos webométricos têm analisado conexões e relações entre websites de organizações dos mais variados tipos: universidades, instituições de pesquisa, empresas, associações, organizações em geral, entre outros. No caso de partidos políticos, Park, Kim e Barnett (2004) analisaram a rede de comunicação entre os partidos políticos Coreanos e a web num período de dois anos, mostrando que as redes de conexões ficaram mais densas ao longo da pesquisa, e que a discussão política na web vem crescendo no tempo.

A conexão entre websites políticos na Coreia do Sul também foi observada por Park e Thelwall (2008). No estudo, os autores certificaram que os membros da Assembleia Nacional da Coreia do Sul têm mais conexões com websites de festas do que com websites institucionais. Mukherjee (2009) utilizou técnicas webométricas para analisar popularidade de websites de partidos políticos indianos e sua evolução no tempo por meio de análise de links e do sistema Wayback Machine.

Romero-Frías e Vaughan (2010) exploraram o universo de 96 websites de partidos da Europa. Os autores procuraram entender a relação dos links que os partidos políticos recebiam na web com a identidade ideológica de cada partido, fatos históricos e a linguística. $\mathrm{Na}$ análise estatística de links recebidos verificou que há bastante diferença entre os partidos políticos estudados de diversos países do continente Europeu. Posteriormente, os partidos políticos espanhóis também foram estudados pelos mesmos autores que verificaram se a análise de links de websites da mídia e de partidos políticos espanhóis poderia prover novas descobertas nas interações entre estes agentes, a partir de dados de links recebidos e de colinks. Os resultados mostraram que existiam mais links entre os websites da mídia e partidos da mesma orientação política, do que entre aqueles com orientações políticas diferentes (ROMERO-FRÍAS; VAUGHAN, 2012).

Estudos de menção web com a temática política também foram realizados por Lin e Park (2011), que analisaram as menções de 18 membros da Assembleia Nacional da Coréia do Sul. Na coleta de dados foi identificada a visibilidade que cada membro apresentava na web, sendo as menções web localizadas em várias plataformas, como websites de notícias, blogs e imagens. A análise constatou que os membros que tem uma melhor carreira no mundo político apresentam melhor visibilidade no mundo virtual. Dois anos depois, os autores investigaram a relação dos políticos coreanos do sul com o montante financeiro que receberam em doações do público. $\mathrm{Na}$ análise foi verificado que os políticos com mais visibilidade na web tendem a receber mais doações financeiras, revelando assim uma correlação positiva entre a visibilidade das menções web e as doações recebidas (LIN; PARK, 2013).

As menções web podem ser analisadas em um âmbito geral, em toda a web, ou em nichos específicos, como no caso das duas situações analisadas por Lin e Park. Ao se analisar um nicho ou grupo específico de websites, as menções web podem trazer resultados mais confiáveis para uma investigação científica, pois nestes casos, em geral, as fontes são menos dispersas e conhecidas; e existe, no processo de publicação de conteúdo em websites oficiais, um compromisso institucional maior com a confirmação das informações, menções e de suas fontes. 
Uma prática realizada durante o desenvolvimento de campanhas políticas são as articulações de partidos para unir forças por meio de coligações partidárias. Essas coligações partidárias consistem "[...] na união de dois ou mais partidos que apresentam os seus candidatos em conjunto para uma determinada eleição." (TODA POLÍTICA, 2015). Neste sentido, é comum que os partidos políticos mantenham relações entre eles no mundo real além das coligações partidárias, e essas relações podem também ocorrer no meio virtual por menções web.

O objetivo deste artigo é analisar as conexões por menção web entre os websites dos partidos políticos com representação no Senado Federal brasileiro. Para tanto, foram obtidos os seguintes indicadores: tamanho de website, quantidade de menções web textuais existentes entre os websites destes partidos políticos (menções recebidas e menções emitidas); em seguida, foi calculada a correlação entre os indicadores mencionados e a quantidade de representantes destes partidos no Senado. As menções web também foram analisadas qualitativamente, com a finalidade de levantar categorias que representassem o contexto em que as menções web foram realizadas entre estes partidos políticos.

\section{PROCEDIMENTOS METODOLÓGICOS}

Esta pesquisa utiliza técnicas de webometria e caracteriza-se pelas abordagens quantitativa e qualitativa, com a finalidade de quantificar as menções web entre os websites dos partidos do Senado, categorizar e interpretar os dados associados a estas conexões.

A escolha dos partidos políticos com representação no Senado Federal brasileiro (http://www12.senado.leg.br), ocorreu em virtude desta instituição ser composta por senadores que representam todos os estados do Brasil. De acordo com o Senado (2017), a instituição é composta de 81 senadores com representação de 18 partidos políticos.

A tabela 1 apresenta os partidos políticos com representação em exercício no Senado Federal selecionados.

Tabela 1: Partidos políticos selecionados

\begin{tabular}{l|r}
\hline Partido Político & Representação \\
\hline Partido do Movimento Democrático do Brasil (PMDB) & 21 \\
\hline Partido da Social Democracia Brasileira (PSDB) & 11 \\
\hline Partido dos Trabalhadores (PT) & 9 \\
\hline Partido Progressista (PP) & 7 \\
\hline Democratas (DEM) & 4 \\
\hline Partido da República (PR) & 4 \\
\hline Partido Socialista Brasileiro (PSB) & 4 \\
\hline Partido Social Democrático (PSD) & 4 \\
\hline Partido Democrata Trabalhista (PDT) & 3 \\
\hline Podemos (PODE) & 3 \\
\hline Partido Trabalhista Brasileiro (PTB) & 2 \\
\hline Partido Comunista do Brasil (PCdoB) & 1 \\
\hline Partido Popular Socialista (PPS) & 1 \\
\hline Partido Republicano Brasileiro (PRB) & 1 \\
\hline Partido Republicano da Ordem Social (PROS) & 1 \\
\hline Partido Social Cristão (PSC) & 1 \\
\hline Partido Trabalhista Cristão (PTC) & 1 \\
\hline Rede Sustentabilidade (REDE) & 1 \\
\hline Sem Partido & 2 \\
\hline Totais & 81 \\
\hline Fonte Adaptado de Senado Fedral (2017)
\end{tabular}

Fonte: Adaptado de Senado Federal (2017).

Diante dos partidos políticos apresentados, buscou-se pelo website oficial de cada partido. Os respectivos websites estão representados no quadro 1.

Quadro 1: Websites dos partidos políticos

\begin{tabular}{|l|l|}
\hline Partido & Website \\
\hline DEM & $\underline{\text { http://www.dem.org.br }}$ \\
\hline PCdoB & $\underline{\text { http://www.pcdob.org.br }}$ \\
\hline PDT & $\underline{\text { http://www.pdt.org.br }}$ \\
\hline PMDB & $\underline{\text { http://www.pmdb.org.br }}$ \\
\hline PODE & $\underline{\text { http://www.podemos.org.br }}$ \\
\hline PP & $\underline{\text { http://www.pp.org.br }}$ \\
\hline PPS & $\underline{\text { http://www.pps.org.br }}$ \\
\hline PR & $\underline{\text { http://www.partidodarepublica.org.br }}$ \\
\hline PRB & $\underline{\text { http://www.prb10.org.br }}$ \\
\hline PROS & $\underline{\text { http://www.pros.org.br }}$ \\
\hline PSB & $\underline{\text { http://www.psb40.org.br }}$ \\
\hline
\end{tabular}




\begin{tabular}{|l|l|}
\hline PSC & $\underline{\text { http://www.psc.org.br }}$ \\
\hline PSD & $\underline{\text { http://www.psd.org.br }}$ \\
\hline PSDB & $\underline{\text { http://www.psdb.org.br }}$ \\
\hline PT & $\underline{\text { http://www.pt.org.br }}$ \\
\hline PTB & $\underline{\text { http://www.ptb.org.br }}$ \\
\hline PTC & $\underline{\text { http://www.ptc36nacional.com.br }}$ \\
\hline REDE & $\underline{\text { http://www.redesustemtabilidade.org.br }}$ \\
\hline
\end{tabular}

Fonte: Dados da Pesquisa (2017).

A partir das informações preliminares ocorreu o início das análises quantitativa e qualitativa. A coleta de dados teve como base o buscador Google, realizada no dia 12 de dezembro de 2017 para a mensuração quantitativa e a análise qualitativa desses resultados recuperados foram analisadas entre o dia 12 e 15 de dezembro.

A obtenção dos dados teve como base a escolha das siglas de cada partido político, uma vez que os partidos são mais popularmente conhecidos e frequentemente citados pelas suas siglas do que pelos seus nomes por extenso.

Para a primeira estratégia de busca correspondente ao 'tamanho do website', utilizou-se a busca com o operador 'site:' e endereço do website de cada partido, conforme o exemplo: site:partido.org.br; Em relação à apuração das menções web textuais de cada partido, utilizou-se o operador 'site:' seguido do endereço do website do partido mais a sigla do partido que está sendo mencionada nos websites, como o exemplo a seguir: site:partidoA.org.br 'partidoB'.

A correlação de Pearson foi mensurada sobre os indicadores coletados, na qual foi utilizada a junção de duas variáveis aplicadas no software SPPS versão 22. Ademais, todos os dados da pesquisa foram tabulados em planilhas do Excel 2013. Para geração do grafo apresentado, foram utilizados os softwares Ucinet e Netdraw.

A análise qualitativa das menções web existentes nos websites dos partidos foi realizada item por item da lista de resultados que o buscador Google recuperou com as estratégias de busca de menções web descritas. Este processo também permitiu a exclusão de duplicidades ou ambiguidades de siglas mencionadas nas páginas recuperadas, pois as siglas como PODE, REDE, PR, DEM traziam alguns resultados, com derivações de palavras e contextos, que não correspondiam às respectivas siglas.

\section{ANÁLISE DOS RESULTADOS}

Esta seção está dividida em quatro subseções, sendo a primeira relativa ao primeiro indicador: tamanho de website; a segunda, contendo os demais indicadores (menções emitidas e recebidas); a terceira, com a análise de correlação de Pearson entre os indicadores, e por fim, a quarta subseção, que apresenta características qualitativas das menções web entre os partidos políticos.

\subsection{Tamanho de website}

0 primeiro indicador analisado foi o tamanho do site, que consistiu em obter o número de páginas que cada website possui. Os montantes estão apresentados na tabela $2 \mathrm{de}$ acordo com a quantidade de páginas em ordem decrescente.

Tabela 2: Tamanho de website dos partidos políticos

\begin{tabular}{l|rr}
\hline Partido político & Tamanho de website / Quantidade de páginas \\
\hline PSDB & 82500 \\
\hline PPS & & 64000 \\
\hline PTB & 37900 \\
\hline PRB & 33000 \\
\hline PT & & 21800 \\
\hline PSD & 12600 \\
\hline PSB & 10100 \\
\hline REDE & 7970 \\
\hline PDT & & 7240 \\
\hline PR & & 6900 \\
\hline DEM & 5060 \\
\hline PMDB & & 4980 \\
\hline PCdoB & 3770 \\
\hline PROS & & 3460 \\
\hline PP & & 298 \\
\hline PTC & & 236 \\
\hline PSC & Fonte: Dados da Pesquisa (2017). \\
\hline PODE & & 39 \\
\hline &
\end{tabular}


Entre os fenômenos observados em relação ao tamanho de website, notou-se que os partidos políticos com representação no Senado Federal estão segmentados em três grandes grupos, o primeiro contando com partidos com quantidade de páginas superior a $10 \mathrm{mil}$ (PSDB, PPS, PTB, PRB, PT, PSD e PSB), o segundo grupo contando com número de páginas entre 8 mil a 3 mil (REDE, PDT, PR, DEM, PMDB, PCdoB e PROS), e o terceiro grupo que tem o número de páginas inferior a 3 mil (PP, PTC, PSC, e PODE).

$O$ resultado apontou uma diferença bastante significativa entre os partidos políticos em relação ao tamanho de website. Enquanto o PSDB apresentou mais que o dobro da quantidade de páginas de 16 partidos, com exceção dos PPS, verificou-se partidos apresentando website com quantidades bastante pequenas de páginas, como no caso de PP, PTC, PSC e PODE, que juntos não somam mil páginas.

\subsection{Websites e menções web}

Para mensurar os indicadores de menções emitidas e recebidas entre os websites dos partidos políticos representados no Senado Federal, foi gerada uma matriz que representa a quantidade de menções web existentes entre os websites destes partidos.

Os resultados obtidos estão dispostos na tabela 3, que apresenta os websites dos partidos em suas linhas com a quantidade de menções emitidas, ou realizadas (partidos citantes); e a quantidade de menções recebidas por partido em suas colunas (partidos citados).

Tabela 3: Matriz das conexões por menções web

\begin{tabular}{|c|c|c|c|c|c|c|c|c|c|c|c|c|c|c|c|c|c|c|}
\hline \multirow{2}{*}{ Website } & \multicolumn{18}{|c|}{ Menções web } \\
\hline & DEM & PCdoB & PDT & PMDB & PODE & $\mathrm{PP}$ & PPS & PR & PRB & PROS & PSB & PSC & PSD & PSDB & PT & PTB & PTC & REDE \\
\hline DEM & & 26 & 51 & 66 & 0 & 68 & 53 & 23 & 15 & 6 & 55 & 30 & 56 & 72 & 90 & 54 & 7 & 5 \\
\hline PCdoB & 50 & & 77 & 77 & 3 & 20 & 17 & 10 & 12 & 4 & 72 & 9 & 18 & 79 & 140 & 12 & 5 & 20 \\
\hline PDT & 68 & 116 & & 126 & 1 & 80 & 72 & 5 & 56 & 16 & 139 & 45 & 67 & 107 & 187 & 92 & 23 & 66 \\
\hline PMDB & 68 & 55 & 68 & & 0 & 72 & 65 & 8 & 41 & 33 & 70 & 52 & 74 & 98 & 129 & 67 & 11 & 11 \\
\hline PODE & 0 & 0 & 0 & 0 & & 0 & 0 & 0 & 0 & 0 & 0 & 0 & 0 & 0 & 0 & 0 & 0 & 0 \\
\hline PP & 1 & 0 & 0 & 1 & 0 & & 0 & 0 & 0 & 2 & 1 & 0 & 1 & 0 & 1 & 0 & 0 & 1 \\
\hline PPS & 77 & 69 & 75 & 87 & 0 & 71 & & 13 & 47 & 26 & 101 & 59 & 86 & 92 & 100 & 66 & 40 & 12 \\
\hline PR & 61 & 38 & 56 & 67 & 0 & 58 & 56 & & 54 & 30 & 58 & 53 & 60 & 60 & 73 & 69 & 26 & 0 \\
\hline PRB & 96 & 95 & 122 & 208 & 1 & 89 & 84 & 65 & & 55 & 132 & 96 & 118 & 163 & 171 & 110 & 81 & 10 \\
\hline PROS & 48 & 34 & 62 & 78 & 0 & 65 & 36 & 12 & 19 & & 65 & 35 & 64 & 66 & 70 & 34 & 10 & 1 \\
\hline PSB & 56 & 62 & 66 & 69 & 0 & 56 & 61 & 24 & 51 & 24 & & 51 & 59 & 66 & 67 & 60 & 27 & 34 \\
\hline PSC & 0 & 0 & 0 & 0 & 0 & 0 & 0 & 0 & 0 & 0 & 0 & & 0 & 0 & 0 & 0 & 0 & 0 \\
\hline PSD & 34 & 80 & 46 & 66 & 0 & 96 & 51 & 9 & 50 & 26 & 85 & 56 & & 115 & 104 & 68 & 19 & 3 \\
\hline PSDB & 237 & 95 & 132 & 425 & 1 & 176 & 188 & 47 & 94 & 69 & 203 & 99 & 160 & & 502 & 136 & 82 & 8 \\
\hline $\mathrm{PT}$ & 301 & 379 & 249 & 498 & 0 & 219 & 116 & 34 & 118 & 69 & 297 & 146 & 141 & 532 & & 118 & 25 & 24 \\
\hline PTB & 82 & 57 & 87 & 248 & 0 & 79 & 69 & 18 & 68 & 33 & 96 & 70 & 77 & 125 & 116 & & 58 & 2 \\
\hline PTC & 1 & 1 & 2 & 20 & 0 & 3 & 0 & 2 & 7 & 1 & 1 & 5 & 2 & 9 & 11 & 2 & & 1 \\
\hline REDE & 63 & 30 & 65 & 146 & 0 & 39 & 80 & 0 & 14 & 36 & 136 & 25 & 43 & 97 & 110 & 34 & 1 & \\
\hline
\end{tabular}

Fonte: Dados da Pesquisa (2017).

A partir da tabela 3, podemos perceber que nem todos os websites dos partidos políticos com representação no Senado Federal fizeram menções web dos partidos estudados. Os websites do PSC e do PODE, por exemplo, não fazem menção a nenhum dos outros partidos do Senado (quantidade de menções $=0$ ), resultado que é consistente com o fato de que são os partidos que apresentam o menor tamanho de website (conforme tabela 2).

O PSDB e o PT foram os partidos que mais receberam menções web de um único website. O PSDB foi mencionado em 532 páginas do website do PT, isso corresponde a quase $32 \%$ de todas as menções que recebeu em relação a todos os websites em estudo (1681 menções). Já o PT recebeu menção em 502 páginas do website do PSDB, sendo quase $27 \%$ do total de menções web feitas ao partido pelos websites analisados (1871 menções). Vale destacar que, neste caso, as maiores quantidades de menções web entre os partidos ocorreram entre siglas com significativa representação que se caracterizam como adversárias políticas, considerando o contexto corrente da política nacional e a história recente de alternância na presidência do governo executivo federal, envolvendo 22 anos de disputas, interações e sucessões entre os anos 1995 e 2016.

0 panorama das menções web emitidas e recebidas também pode ser observado na figura 1. 


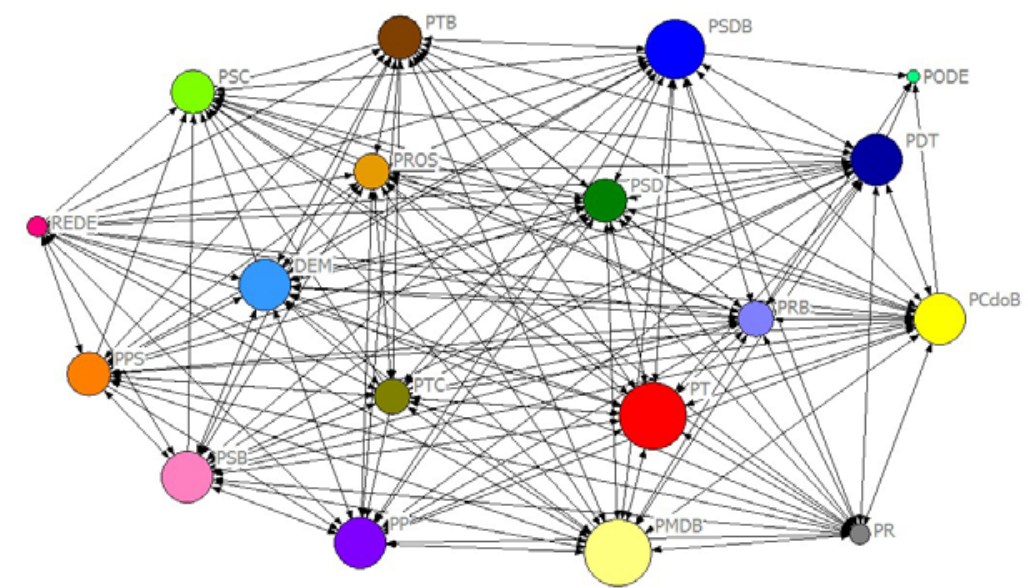

Figura 1: Conexões entre os partidos políticos

Fonte: Dados da pesquisa (2017).

A figura 1 representa o cenário das menções recebidas e menções emitidas. Os nós representam cada partido e seu tamanho está relacionado com a quantidade de menções recebidas por cada website dos partidos estudados; desta forma, os nós, ou círculos, maiores representam os partidos que receberam mais menções dos demais partidos, considerando o total de menções web recebidas por cada partido.

O PMDB, PT e PSDB são os partidos que receberam maior número de menções web, emitidas pelos outros partidos em estudo. O PT apareceu em todas as possibilidades de menções recebidas (recebeu menções de 15 websites, dos 17 websites de partidos que emitiram menções web), ficando sempre entre as três primeiras siglas mais mencionadas; 0 PMDB também ficou entre as três primeiras siglas mais mencionadas em 12 situações, e o PSDB em 11 situações. Neste caso, o fato de um partido ter exercido a presidência da república nos últimos 24 anos é compatível com o resultado das siglas que receberam maior número de menções web. Vale ressaltar que, além do PSDB e do PT, o PMDB também entrou para o grupo de partidos que exerceu a presidência do país mais recentemente.

No outro lado deste espectro, o PODE foi o partido que menos recebeu menção web de outros partidos, 6 menções de 4 partidos: PCdoB, PDT, PRB e PSDB; resultado que pode ser explicado pelo fato de ter alterado seu nome em 2016, pois era denominado anteriormente de Partido Trabalhista Nacional (PTN).

A tabela 4 apresenta a quantificação das menções emitidas e recebidas de cada partido político.

Tabela 4: Quantitativo das menções web

\begin{tabular}{l|r|r}
\hline \multirow{2}{*}{ Partidos } & \multicolumn{2}{|c}{ Menções web } \\
\cline { 2 - 3 } & \multicolumn{1}{|c}{ Emitidas } & \multicolumn{1}{c}{ Recebidas } \\
\hline DEM & 677 & 1243 \\
\hline PCdoB & 625 & 1137 \\
\hline PDT & 1266 & 1158 \\
\hline PMDB & 922 & 2182 \\
\hline PODE & 0 & 6 \\
\hline PP & 8 & 1191 \\
\hline PPS & 1021 & 948 \\
\hline PR & 819 & 270 \\
\hline PRB & 1696 & 164 \\
\hline PROS & 699 & 430 \\
\hline PSB & 833 & 1511 \\
\hline PSC & 0 & 831 \\
\hline PSD & 908 & 1026 \\
\hline PSDB & 2654 & 1681 \\
\hline PT & 3266 & 1871 \\
\hline PTB & 1285 & 922 \\
\hline PTC & 68 & 415 \\
\hline REDE & 919 & 198 \\
\hline
\end{tabular}

Fonte: Dados da Pesquisa (2017). 
Diante das totalizações de menções emitidas e recebidas por cada partido, podemos perceber que ocorreu uma grande diversidade. Dos 18 partidos em estudo, 9 emitiram mais menções web que receberam (PDT, PPS, PR, PRB, PROS, PSDB, PT, PTB e REDE) e 9 receberam mais menções web que emitiram (DEM, PCdoB, PMDB, PODE, PP, PSB, PSC, PSD e PTC).

0 PMDB (com 2182 menções), o PT (1871 menções) e o PSDB (1681 menções) foram os partidos que mais receberam menções web em todos os possíveis cenários. Estes resultados também são consistentes com o fato destas siglas terem ocupado, ou participado de coalisões que compuseram o governo executivo federal.

Em relação às menções emitidas, os partidos que mais mencionaram os demais em seus websites são o PT, com 3266 menções web, e o PSDB com 2654 menções.

\subsection{Correlação entre os indicadores}

Após a coleta de dados e a obtenção dos indicadores, foi calculado o nível de correlação de cada variável quantitativa. Para tanto, foi aplicado o teste de correlação linear de Pearson, que segundo Barbetta (2014) gera um valor estará sempre entre o intervalo de 1 e -1; quanto mais próximo das extremidades for o valor resultante, maior será a correlação; e quanto mais próximo de zero, menor será a correlação.

O quadro 2 apresenta os níveis de correlação linear de Pearson entre muito forte a muito fraca, ou a inexistência de correlação.

Quadro 2: Classificação de Correlação Linear de Pearson

\begin{tabular}{|l|l|}
\hline \multicolumn{1}{|c|}{ Índice (r) (positivo (+) ou negativo (-)) } & \multicolumn{1}{c|}{ Descrição } \\
\hline$(\mathrm{r})=0$ & Não existe correlação linear. \\
\hline $0,001 \leq(\mathrm{r})<0,199$ & Correlação linear bem fraca. \\
\hline $0,200 \leq(\mathrm{r})<0,399$ & Correlação linear fraca. \\
\hline $0,400 \leq(\mathrm{r})<0,699$ & Correlação linear moderada. \\
\hline $0,700 \leq(\mathrm{r})<0,899$ & Correlação linear forte. \\
\hline$(\mathrm{r}) \geq 0,900$ & Correlação linear bem forte \\
\hline
\end{tabular}

Fonte: Adaptado de Shimakura (2006).

A aplicação de correlação linear teve como base quatro variáveis quantitativas, compostas pelos indicadores obtidos na análise de dados: 'Tamanho do Website', 'Menções Web Emitidas' e 'Menções Web Recebidas'. Além dos três indicadores coletados, a correlação linear também foi aplicada para a quantidade de representantes que cada partido político tem no Senado Federal, ou 'Representantes no Senado'.

0 quadro 3 apresenta os cruzamentos das variáveis selecionadas, o valor de r, e a classificação da correlação linear obtida.

Quadro 3: Correlações Lineares obtidas

\begin{tabular}{|l|c|c|}
\hline Variáveis de relação & $\begin{array}{c}\text { Valor } \\
\text { (r) }\end{array}$ & $\begin{array}{c}\text { Classificação da } \\
\text { Correlação Linear }\end{array}$ \\
\hline Tamanho de website x Menções Emitidas & 0,633 & Moderada \\
\hline Tamanho de website x Menções Recebidas & 0,268 & Fraca \\
\hline Tamanho de website x Representantes no Senado & 0,116 & Bem Fraca \\
\hline Menções Emitidas x Menções Recebidas & 0,507 & Moderada \\
\hline Menções Emitidas x Representantes no Senado & 0,332 & Fraca \\
\hline Menções Recebidas x Representantes no Senado & 0,742 & Forte \\
\hline
\end{tabular}

Fonte: Dados da Pesquisa (2017).

Das seis relações averiguadas, três valores geraram correlação linear classificada de moderada a forte. 0 cruzamento entre as variáveis 'Menções Emitidas' e 'Menções Recebidas' obteve o valor de 0,507 sendo classificada como moderada; isto significa que, nos dados levantados, houve a tendência de forma moderada, de que os partidos que mais fizeram ou emitiram menções web, também foram aqueles que receberam mais menções.

As variáveis 'Tamanho de Website' e 'Menções Emitidas' quando cruzadas também foram classificadas como correlação linear moderada, no valor de 0,633. Com a mesma classificação do cruzamento descrito anteriormente, estas variáveis variaram no mesmo sentido, de maneira moderada, porém de uma forma um pouco mais intensa do que a anterior.

A única correlação linear classificada como forte foi o confronto das variáveis 'Menções Recebidas' com a quantidade de 'Representantes no Senado', tendo como resultado o valor obtido de 0,742 . Neste caso, quanto maior era a representação dos partidos políticos no Senado Federal, maior foi a sua quantidade de menções recebidas dos websites dos partidos políticos brasileiros. 
Vale ainda observar que nenhuma correlação averiguada teve como resultado um valor negativo; isto significa que nenhuma combinação de variáveis analisadas teve resultados inversamente proporcionais; independentemente dos níveis de classificação obtidos nas correlações, os valores das variáveis, quando confrontados, cresceram ou diminuíram juntos, no mesmo sentido.

\subsection{Análise qualitativa e categorias de menção web}

No intuito de identificar como os partidos políticos mencionam os demais partidos em seus websites institucionais, foi feita uma análise do conteúdo de cada página que continha menções das siglas dos partidos pesquisados.

Ao todo foram 17666 páginas que emitiram menções web de todos os partidos analisados. 0 conteúdo das páginas teve como concentração notícias de cunho político. Após a leitura de cada informação que continha as menções, as mesmas foram classificadas em seis categorias: Acusação, Votação, Comissão, Eleição, Pessoal e Outros. Os resultados preliminares envolvendo estas categorias são apresentados a seguir:

As páginas que continham o conteúdo de "Acusação" concentraram em três vertentes: As menções web estavam em contexto de acusação de um partido diretamente a outro partido, ou de informações vinculadas em outros meios de comunicação dentro do website do partido que emite a menção; menções de apoio a um partido quando o mesmo acusava outro partido; e menções de defesa a um partido quando o mesmo recebia acusação de um terceiro ou mais partidos. Nesta categoria de acusação, destacaram-se as menções web realizadas em documentos que descrevem o envolvimento de representantes do Senado Federal e da Câmara dos Deputados.

A classificação "Votação" trata de resultados de votações referentes a comissões, projetos de leis, tanto nas esferas do Senado, da Câmara de Deputados (Federal e/ou Estadual) e Câmaras Municipais. As informações seguiram duas linhas, sendo uma relacionada a resultados de votação em si; e a outra relacionada a resultados de comum acordo com o partido, ou em desacordo.

A categoria "Comissão" trata de páginas que continham informações relacionadas à formação de comissões, bem como as interações que os partidos exercem sobre elas. Em muitas das situações, os websites também abordavam as questões de apoio ou desaprovação de partidos perante posições expressas ou ações realizadas no âmbito das comissões formadas.

As páginas dos websites que tinham como conteúdo "Eleição" envolveram quatro linhas. As menções web estavam associadas a questões de coligação de partidos, bem como campanhas e encontros; menções vinculadas a debates oriundos de primeiro turno, quanto segundo turno de eleições; as menções também foram observadas em pesquisas eleitorais em todas as esferas; e também em resultados oficiais computados os votos das urnas. Nesta categoria foi frequente a ocorrência de menções web em contextos de participação de coligações partidárias e de formação de legendas.

A categoria intitulada "Pessoal" diz respeito a menções web que vinculavam a sigla do partido à ficha ou currículo de uma pessoa; por exemplo, quando um deputado mostra o seu histórico informando a quais partidos já foi filiado.

Os conteúdos que foram classificados como "Outros" envolveram uma grande diversidade de informações. As menções apareceram em Charges contra partidos, ou citando pessoa vinculada a um determinado partido, prêmios recebidos, participação em eventos, notas de falecimento, notas de repúdio e históricos de partidos.

\section{CONSIDERAÇÕES FINAIS}

As técnicas webométricas têm sido objeto de estudo há mais de 20 anos, e como um tema diretamente ligado à dinâmica web, tende a incorporar aperfeiçoamentos continuamente no tempo. Estudos de frequência e de contexto de menções web podem auxiliar e enriquecer análises de informações disponíveis na grande rede em geral, e também têm sido utilizados mais especificamente no contexto político.

A análise das menções web existentes entre os websites dos partidos políticos com representação no Senado Federal brasileiro foi realizada e cabe aqui destacar os principais resultados: todos os partidos políticos receberam menção web da população em estudo; e somente dois partidos com menor representação no Senado não fizeram menção de outros partidos em seus websites, significando que a grande maioria dos partidos interage e cita os demais, sejam eles aliados ou adversários políticos. 
Em relação ao tamanho do website dos partidos políticos, o estudo mostrou que o conjunto de partidos apresentou características bastante variáveis, do PSDB e PPS com mais de 60.000 páginas a partidos com menos de 50 páginas, como o PSC e o PODE. Esperava-se que partidos com maior representação no Senado tivessem também websites de maior tamanho, com mais conteúdo. Entretanto, a correlação entre tamanho do website e a quantidade de representação no Senado foi bem fraca, a menor encontrada nesta pesquisa. A despeito disto, tamanho de website em geral significa maior investimento e infraestrutura para gestão e geração de conteúdo.

A matriz de conexões por menções web entre os 18 partidos políticos com representação no Senado Federal é relativamente bem distribuída, com valores maiores e destaque para os três partidos com maior representação no Senado: PMDB com 21 senadores; PSDB com 11 senadores; e PT com 9 senadores. No outro extremo, observaramse as duas exceções: PSC e PODE (PODEMOS) não fizeram nenhuma citação aos demais partidos, estão entre as menores representações no Senado, com um e três representantes, respectivamente; e também possuem os websites com menor quantidade de páginas dentre os pesquisados.

Além de contar com a maior representação no Senado PMDB, PSDB e PT emitiram e receberam a maior quantidade de menções web por website de partido pesquisado, e também receberam a maior quantidade totalizada de menções web, a soma de menções web realizadas por todos partidos. Estes resultados são plenamente compatíveis com o fato destes três partidos terem se revezado no exercício da presidência da república nos últimos 24 anos. O PSDB ocupou o governo do ano de 1995 até o ano 2002; o PT, de 2003 a agosto de 2016; e o PMDB, de setembro de 2016 a 2018. Vale lembrar que o PMDB participou, com o PSDB e depois com o PT, dos dois governos anteriores; e o PSDB participa do governo do PMDB no atual mandato.

Partidos com maior representação também contam, em geral, com os maiores quadros de afiliados, maior representação nos níveis federal, estadual e municipal, e, neste caso, ocuparam cargos de destaque na história política recente do país. Estes ocupantes de cargos públicos, tais como presidente da república, presidente do Senado, presidente de Câmara dos Deputados, presidente de partido, presidente e membros de comissões parlamentares, lideranças, normalmente pertencem a partidos políticos e, no exercício de seu cargo, têm o poder de gerar pautas de discussão e de votação, que influenciam pautas jornalísticas. Consequentemente, tendem a atrair e receber mais menções web.

Além destes casos, existem políticos afiliados, ou profissionais indicados por partidos políticos, que são alvos de investigações e de acusações e que frequentemente são mencionados pelos adversários políticos junto com sua sigla. Como trabalhos futuros, destacamos a possibilidade de detalhar a análise de citações web positivas, ou de apoio, e negativas, ou críticas, por partido político individualmente.

A única correlação positiva forte encontrada foi entre a quantidade de representantes dos partidos políticos no Senado Federal, e a quantidade de menções recebidas. Também foram encontradas correlações positivas moderadas entre tamanho de website e menções emitidas; e menções emitidas e menções recebidas; que são resultados lógica e naturalmente esperados.

Podemos observar que os partidos políticos com representação no Senado Federal interagem também no ambiente web e que seus websites contêm registros dos laços existentes entre suas entidades ou entre seus membros, na forma de citações web. Os resultados deste trabalho reforçam os argumentos de que as menções web são um registro representativo do que ocorre no mundo real.

\section{REFERÊNCIAS}

ARAÚJO JÚNIOR, R. H. Precisão no processo de busca e recuperação da informação. Brasília: Thesaurus, 2007.

BARBETTA, P. A. Estatística. Aplicações às Ciências Sociais. Florianópolis: Editora UFSC, 2014.

LIM, Y. S.; PARK, H. W. How do congressional members appear on the web? Tracking the web visibility of South Korean politicians. Government Information Quarterly, v. 28, n. 4, p. 514-521, 2011.

Disponível em: <https://www.infona.pl/resource/bwmeta1.element.elsevier-9ac401c8-a00b-37dcb745-903eab02d575>. Acesso: 20 dez. 2017.

. The structural relationship between politicians' web visibility and political finance networks: a case study of South Korea's National Assembly members. New Media \& Society, v. 15, n. 1, p. 93-108, feb. 2013. Disponível em: 


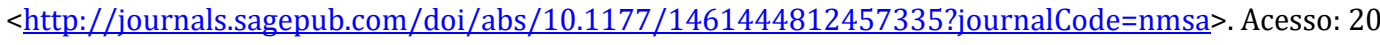
dez. 2017.

MUKHERJEE, B. Link analysis of Indian political parties' web sites: a temporal comparison. Annals of Library and Information Studies, v. 56, p. 201-211, set. 2009. Disponível em:

<http://nopr.niscair.res.in/bitstream/123456789/6568/1/ALIS\%2056\%283\%29\%20201-211.pdf>. Acesso em: 20 dez. 2017.

ORDUÑA-MALEA, E.; AGUILO, I. F. Cibermetría: Midiendo el espacio red. Barcelona: Editora UOC, 2014.

PARK, H. W.; THELWALL, M. Links analysis: Hyperlink patterns and social structure on politicians' Web sites in South Korea. Quality \& Quantity, v. 42, n. 5, p. 687-697, out. 2008. Disponível em:<https://link-springer-com.ez46.periodicos.capes.gov.br/article/10.1007\%2Fs11135-007-9109z>. Acesso em 20 dez. 2017.

PARK, H. W.; KIM, C.-S.; BARNETT, G. A. Socio-Communicational Structure among Political Actors on the Web in South Korea. New Media \& Society, v. 6, n. 3, p. 403-423, jun. 2004. Disponível em:

<http://journals.sagepub.com.ez46.periodicos.capes.gov.br/doi/10.1177/1461444804042522>.

Acesso em: 20 dez. 2017.

ROMERO-FRÍAS, E; VAUGHAN, L. European Political Trends Viewed Through Patterns of Web Linking. Journal of the American Society for Information Science and Technology, v. 61, n. 10, p. 2109-

2121, Out. 2010. Disponível em: <http://web.a-ebscohost-

com.ez46.periodicos.capes.gov.br/ehost/pdfviewer/pdfviewer?vid=3\&sid=2417c3fa-4f77-4250-a7574cf517c29e6a\%40sessionmgr4007>. Acesso em: 20 dez. 2017.

. Exploring the relationships between media and political parties through web hyperlink analysis: the case of Spain. Journal of the American Society for Information Science and Technology, v. 63, n. 5, p. 967-976, maio. 2012. Disponível em: <

http://onlinelibrary.wiley.com/doi/10.1002/asi.22625/abstract>. Acesso em: 20 dez. 2017.

SENADO FEDERAL. Senadores. Disponível em: <http://www25.senado.leg.br/web/senadores/emexercicio >. Acesso em: 10 dez. 2017.

SHIMAKURA, S. E. Interpretação do coeficiente de correlação. 2006. Disponível em:

<http://leg.ufpr.br/ silvia/CE003/node74.html>. Acesso em 20 dez. 2017.

TODA POLÍTICA. Como funciona uma coligação partidária. 2015. Disponível em:

<https://www.todapolitica.com/como-funciona-uma-coligacao-partidaria/>. Acesso em: 12 dez. 2017.

Editores do artigo: Enrique Muriel-Torrado, Edgar Bisset Alvarez, Camila Barros. 